\title{
Examining Knowledge Transfer Channels for Development of Environment Sector in Sindh
}

\author{
JAGUL HUMA LASHARI* $\dagger$, ARABELLA BHUTTO*, QAZI MUHAMMAD MOINNUDDIN ABRO*, \\ ZAHID ALI MEMON*, AND IFFAT BATOOL NAQVI* \\ RECEIVED ON 06.06.2017 ACCEPTED ON 13.11.2017 \\ ABSTRACT
}

\begin{abstract}
It is well understood that the creation and applications of new knowledge is the primary factor that drives economic growth. Aim ofthis research is to examine the KTCs (Knowledge Transfer Channels) in the universities of Sindh, Pakistan leading towards the scientific and technological development of environment sector. This research identified 29 KTCs from literature those were examined, making exploratory interviews with $\mathrm{PhD}$ faculty members of universities offering degrees in field of environment. The identified 29 KTCs are grouped together into 7 groups based on their characteristics. KTC-1: Publications (2-variables); KTC-2: Networking (4-variables); KTC-3: Mobility of Researchers (6variables); KTC-4: Joint Research (5-variables); KTC-5: Intellectual Property with (2-variables); KTC6: Co-operations (6-variables); KTC-7: Institutional Infrastructure (3-variables). Findingsshows, relevancy of KTCs in terms of their role towards the utilization of knowledge capital towards development by means of professional publications from KTC-1, participation of industry staff in conferences and workshops from KTC-2, students working as trainees in the industry and outflow of graduates at M.Phil. level from KTC-3, consultancy of university staff members in the industry from KTC-4, research work in co-operation with research institutes and with consultants from KTC-6 and sharing of physical infrastructure from KTC-7 also shows their impact towards the utilization of knowledge capital for development of environment sector. None of variablefrom KTC-5 related to intellectual property rights shows their impact towards utilization of knowledge capital. This research contributes empirical results of KTCs in universities, with policy implications for future knowledge transfer, which can contribute in the development of society.
\end{abstract}

Key Words: Development, Environment Sector, Knowledge Transfer Channels.

\section{INTRODUCTION}

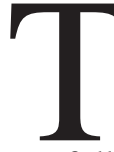

he term KT (Knowledge Transfer) and its dissemination are targeting research findings to specific audiences. The KT activities should be carefully and appropriately considered and outlined in a dissemination plan focused on the needs of audience who will use the knowledge. The KT becomes important part of innovation, universities as a knowledge producing and disseminating institutions play a larger role in the national development [1]. The focus of this research is to present the aspect of KTCs in the universities contributing towards utilization of knowledge capital for development of environment sector.

$\dagger$ Corresponding Author (E-Mail: huma.lashari@yahoo.com)

*Mehran University Institute of Science, Technology \& Development, Mehran University of Engineering \& Technology, Jamshoro.

This is an open access article published by Mehran University Research Journal of Engineering and Technology, Jamshoro under the CC by 4.0 International License. 
It is well understood that the creation and applications of new knowledge is the primary factor that drives economic growth. It is also commonly accepted that universities are an important source of new knowledge, particularly in the areas of science and technology. In this way, it is essential to work as clear picture as conceivable of the systems by which universities research contribute in the development [2]. The UNO highlights the significance of development in the presence of required knowledge. Instruction additionally turns out to be an urgent component for the development as it encourages the change of way of life that is expected to accomplish the manageable examples of utilization and other conduct required to guarantee the necessities of future eras will likewise be met [3].

The process of KT and its utilization can be defined as the means by which mastery, learning, abilities and capacities are exchanged from the information base (for example, universities, research centers or research organization) to those needing that learning; for instance, ventures, social undertakings or not-for-profit organization [4].

The KT relates to the dispersal and utilization of research comes from researchin academic environment, and by industrialistsin applications [5]. The KT depends upon communications amongst researchers and practitioners, as opposed to straight arrangements starting with the requirements of specialists or the necessities of end users. The supporters of these clarifications anticipate that the more managed and extraordinary the communication amongst researchers and practitioners, the more probable use of research knowledge will happen [6]. Not at all like earlier clarifications, has this point of view recommended more noteworthy consideration regarding the connections amongst scientists and practitioners at various phases of research transfer and its utilization. The informal contacts are identified as most intriguing arrangements of components connecting researchers and practitioners, cooperation in funding bodies, and the transmission of research project reports to end user organizations [7].
This research identifies KTC for transfer of knowledge capital from universities to the end users of such knowledge capital which can contribute in the societal development. Identified KTC are further analyzed by means their role in the transfer of knowledge capital in the universities in Sindh offering degrees in the environment contributing in the development of environment sector. In the end, the KTC are examined by means of their impact on the utilization of knowledge capital. Structure of this research is comprised of different sections of discussions, starting with introduction; detailed review of literature is presented to identify the KTC. Research presents discussion related to methodology, results and discussions, in the end conclusions and recommendations are presented. Below section presents the review of literature.

\section{LITERATURE REVIEW}

Literature related to knowledge flow from university to end user presents various channels of KT as; knowledge exchange, collaborative research, action research, participatory research, community-based participatory research, coproduction of knowledge, or mode 2 research, involves active collaboration and exchange between researchers and knowledge users throughout the research process from identifying and shaping the research questions to collecting data and interpreting findings and disseminating and applying the results[8]. The quality of university-industry interfaces might be a key factor in promoting innovation, the complex and varied nature of such interfaces need to be understood and explored[9]. A co-ordinated approach is possibly additional tedious, requesting, and asset escalated than different methodologies since it requires the two analysts and information clients to grow new aptitudes, learning, and points of view. In any case, effectively including knowledge users as accomplices in the exploration procedure is a solid indicator that the examination discoveries will be utilized and that the exploration attempt by and large will accomplish a more noteworthy effect [10]. 
Although, there are various channels via which information and know-how are transferred between universities and industry. These include formal and informal, premeditated and unplanned, direct and indirect channels. The SPRU (Science and Technology Policy Research) presented seven key advantages from research for development from past such as: (i) producing new scientific information; (ii) preparing talented graduates; (iii) supporting new logical systems and framing communication; (iv) expanding the capacity for problemsolving; (v) creating new instrumentation and procedures/ methods; (vi) making new firms; and (vii) giving social learning [11]. The knowledge dissemination and exchange components of the knowledge translation process that includes synthesis, dissemination, exchange, and ethically sound application of knowledge [12]. In this regard, the work of universities is depicted as a powerful approach to exchange information to end user organizations [13]. It is found that the best commitment of the scholarly world to development appears as aberrant and impalpable streams of thoughts, information and master help [14]. The principle approach to build the commitment of scholarly world to development is to expand the quantity of (casual) correspondence channels amongst the scholarly community and industry, collective and contracted research exercises seem, by all accounts, to be a great deal more essential type of KT [15]. Counting it, informal contacts are frequently observed to be a typical type of collaboration amongst university and industry [16]. Despite the fact, there are different sorts of joint efforts, altogether described by a skill of working environment [17].

The different types of industry-academia co-operations can bring about an assortment of yields including new instrumentation, approaches, models, licenses, spinoffs. Because of the assortment of exercises and yields, no single measure is completely ready to catch the entire scope of industry-academia coordinated efforts [18]. Systems, including groups of training, information systems, and delicate systems, are conceivably powerful components for information scattering and application on the grounds that their primary design is to associate individuals who may not generally have a chance to communicate, empower discourse, fortify learning, and catch and diffuse information. A training is a gathering of individuals who share a typical concern, an arrangement of issues, or enthusiasm for a subject and who meet up to satisfy both individual and gathering objectives generally centered around enhancing their proficiency. Community oriented connections based on trust and regular cooperation amongst researcher and practitioners are key determinants of successful knowledge transfer activities. As creative ways to deal with trade and spread develop and advance, expanding center must be set around creating markers to assess these procedures and on thoroughly assessing their viability on significant short, medium, and long haul results [12].

The take-up of universities look into depends neither on the qualities of the examination items nor on the emphasis of research on the progression of academic information or the clients' needs; rather it relies upon clients' obtaining endeavors, researchers' adjustment of research items, the force of the connections amongst researchers and clients, and on clients' hierarchical relevant factors [19]. The KT and its use can be characterized as the methods by which mastery, information, abilities and capacities are exchanged from the learning base (for instance, universities, inquire about focuses or research association) to those needing that information; for instance, ventures, social enterprises or nonprofit organization [4]. 
The debate on KT has turned into a subject of awesome enthusiasm to scholastics, industry pioneers and policy makers, as it is currently recognized that such connections are significant for advancement [20]. New and industrially valuable knowledge capital is the after effect of cooperation and learning forms among different performers in advancement frameworks, i.e. researchers, end users, transferring agents, media, and funding organizations. The transfer and utilization of scientific knowledge are non-direct procedures of issue recognizable proof and investigation, correspondence, connection, and learning by and among the different accomplices in the advancement procedure. It is well demonstrated that scholastics add to advancement exercises mostly by delivering new information in specific fields [21].

The lack of interaction between researchers and industries has been identified as a major issue in the developing countries. Although, there are various ways in which academics contribute to innovation, there is widespread gap of research in many developing countries. Discussion presented above shows different aspects of KTC, but gap have been identified in the literature related to assessment of role of KTC towards development. In order to fill this gap in the literature, this research examines role of KTCs towards the development of environment sector. Below section presents methodology used in this study.

\section{MATERIALS AND METHOD}

The above discussed literature identified 29 KTCs by which academic knowledge is transferred to the end users. These KTCs are organized into 7 clusters with respect to their similarity of activities as shown in Fig. 1. KTC: KTC1: Publications with 2 variables; KTC-1.1: Scientific Publications, KTC-1.2: Professional Publications. KTC2: Networking with 4 variables; KTC-2.1:Participation of industry staff in conferences and workshops, KTC-2.2:
Personal contacts of industry people with university staff, KTC-2.3: Personal contacts via membership of professional organizations, KTC-2.4: Personnel contacts via alumni organizations. KTC-3: Mobility of Researchers with 6 variables; KTC3.1: Students working as trainees in the industry, KTC-3.2: Outflow of graduates at: (BE, BS level), KTC-3.3: Outflow of graduates at: (MS, ME, M. Phil level), KTC-3.4: (PhD level), KTC-3.5: Outflow of university staff in the industry, KTC-3.6: Staff holding position both in university and industry/business, KTC-3.7: Temporary staff exchange. KTC-4 Joint Research with 5 variables; KTC-4.1: Joint research projects with the industry funded by HEC, KTC-4.2: Joint research and development projects with the industry, KTC-4.3: Contract research for the industry (Students' Project) without funding by industry, KTC-4.4: Financing of (students' project) by the industry, KTC-4.5: Consultancy of university staff members in the industry. KTC-5: Intellectual Property with 2 variables; KTC-5.1: Patent, KTC-5.2: Copyrights, KTC6: Cooperation with 6 variables; KTC-6.1: Own university, KTC-6.2: Government or private research institutes, KTC6.3: Other universities, KTC-6.4: Commercial laboratories, KTC-6.5: Service providers and KTC-6.6: Cooperation with consultants. KTC-7 Institutional Infrastructure with 3 variables; KTC-7.1: University spin-offs, KTC-7.2: Specific knowledge transfer by TTOs, KTC-7.3: Sharing infrastructure.

This research examines KTC in the universities offering degrees in environment sector in Sindh, Pakistan. To make the empirical implications, faculty members of universities offering degrees in the environment sector having $\mathrm{PhD}$ qualification are selected using case study approach. A case study is a research method involving an up-close, in-depth, and detailed examination of a subject of study (the case), as well as its related contextual conditions [22]. Selected area of degree program is offered in 8 universities in which, 3 universities offer degrees in environmental sciences and 5 offer degrees in 
environmental engineering with $24 \mathrm{PhD}$ faculty members, 12 working in the universities offering degrees in environmental engineering and 12 in environmental sciences. Required data have been collected through detailed interviews with the $\mathrm{PhD}$ faculty members working in the universities in Sindh offering degrees in the environment sector.

Research instrument used in this research is comprised of closed ended questions identified from the literature, 24 semi-structured interviews held on the availability of time of respondents, the aim of semi-structured interviews was focused to explore the KTC.Research questions asked in Semi-structured interviews are often preceded by observation, informal and unstructured interviewing in order to allow the researchers to develop a keen understanding of the topic of interest necessary for developing relevant and meaningful semi-structured questions [23]. Neuman et. al. [24] presented a two-stage study that had two key objectives: to develop a theory about evaluation of utilization in an educational organization and to apply this theory to promote evaluation utilization within the organization. The first stage involved a theoretical conceptualization using a participatory method of concept mapping. The second stage examined the practical implications of this conceptualization in terms of how different stakeholders in the organization perceive the actual and preferable state of utilization within the organization.

The obtained data has been analyzed using statistical packages for social sciences SPSS Version 20. Different techniques have been used to analyze the data to obtained results such as; chi-square test to determine whether there is a significant association between the two variables [25], and cross tabulation which is used as tool that allows comparingthe relationship between two variables [26].

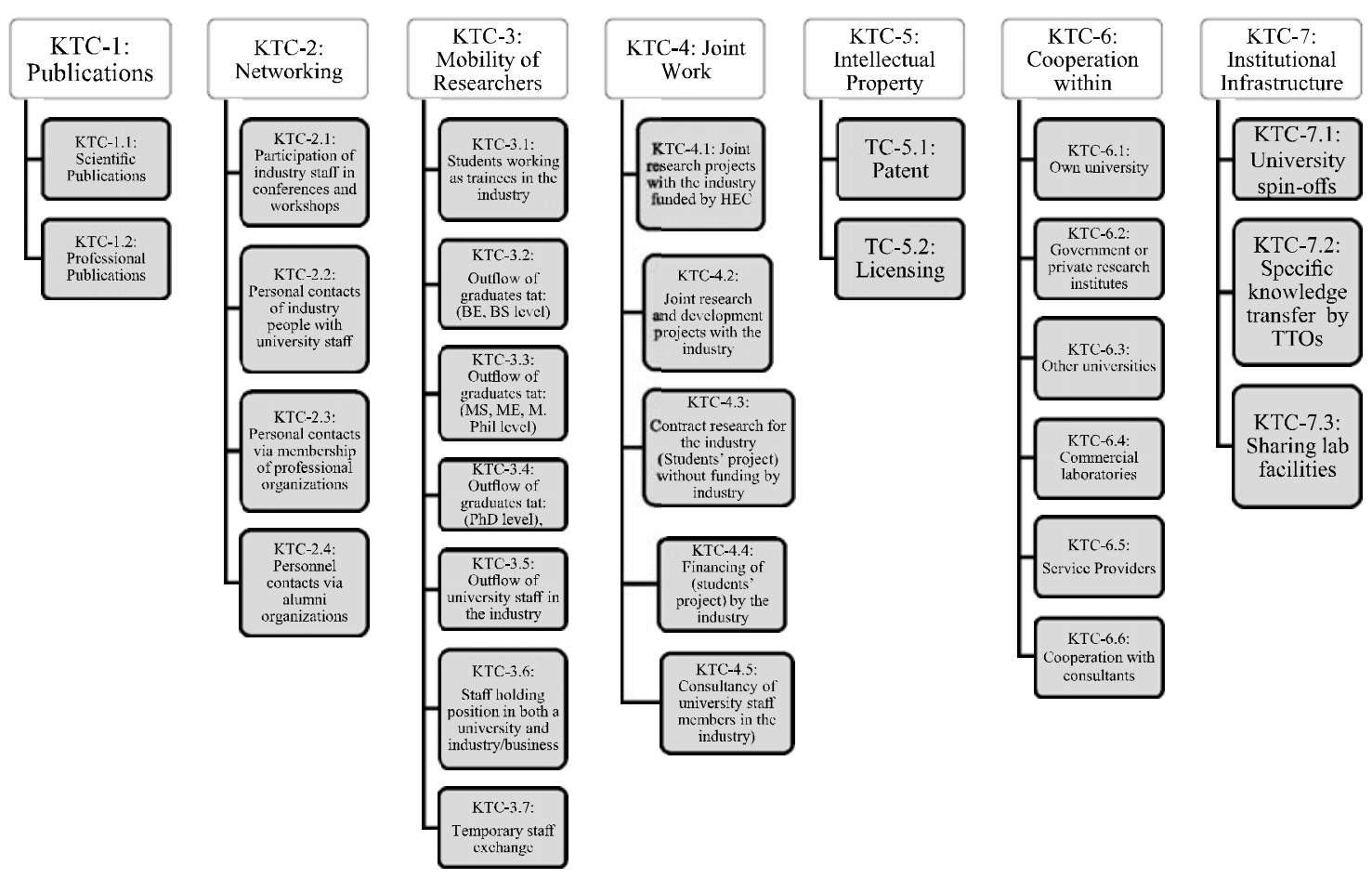

FIG. 1. ACADEMIC KNOWLEDGE TRANSFER CHANNELS 


\section{DATAANALYSIS AND RESULTS}

Results are based on empirical data obtained from the interviews with selected cases of $\mathrm{PhD}$ faculty members of universities offering degrees in environment sector. Responses related to transfer channels of academic knowledge have been collected using developed research instrument. Respondent were asked how they assess their KT through identified channels on three pointing rating scale, ranging from Scale: 1=Never Transferred, $2=$ Slightly Transferred, $3=$ Transferred at most. To assess the utilization of knowledge capital, responses been collected on scale of $0=$ No, $1=$ Yes. Detailed results are discussed below.

The role of KTCs is examined in terms of utilization of knowledge capital making analysis on chi-square test at significance level of 0.05 . Result related to each KTC is presented in Table 1. According to obtained results, in the KTC-1: KT by means of publication KTC-1.2 shows difference with probability value of 0.003 . From the channels of knowledge transfer included in the KTC-2: related to KT through networking shows difference towards utilization in the KTC-2.1: with probability value of 0.023, KTC-2.2: with 0.000, KTC-2.3: with probability value of 0.002 .

Results related to KTC-3 in which knowledge transfer have been assessed by means of mobility of researchers show variations in the KTC-3.3 with probability value of 0.016. Channels of knowledge transfer included in KTC4: related joint research programs shows variation in the KTC-4.5: with probability value of 0.010 . Assessment of KTC-5: by means of IP did not shows variation, while KTC-6: related to cooperation shows variation in the KTC-6.2: with probability value of 0.028 and KTC-6.6: with 0.029 probability value. At the end, channels of KT included from the last KTC-7: the KTC-7.3: KT by means of sharing infrastructure in terms of lab equipment and other services shows variation at significant level with probability value of 0.021 .

TABLE 1. ASSESSMENT OF KNOWLEDGE TRANSFER CHANNELS BASED ON THEIR ROLE TOWARDS UTILIZATION OF KNOWLEDGE CAPITAL

\begin{tabular}{|c|c|c|c|c|c|c|c|c|c|c|c|c|}
\hline \multirow{16}{*}{ 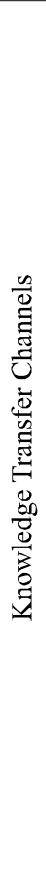 } & No. & \multicolumn{11}{|c|}{ Chi - Square Test Results } \\
\hline & \multirow{2}{*}{ KTC -1} & Variables & \multicolumn{5}{|c|}{ KTC -1.1} & \multicolumn{5}{|c|}{$\mathrm{KTC}-1.2$} \\
\hline & & p. value & \multicolumn{5}{|c|}{0.202} & \multicolumn{5}{|c|}{0.003} \\
\hline & \multirow{2}{*}{ KTC -2} & Variables & \multicolumn{2}{|c|}{ KTC -2.1} & \multicolumn{3}{|c|}{$\mathrm{KTC}-2.2$} & \multicolumn{3}{|c|}{ KTC -2.3} & \multicolumn{2}{|c|}{ KTC -2.4} \\
\hline & & p. value & \multicolumn{2}{|c|}{0.023} & \multicolumn{3}{|c|}{0.000} & \multicolumn{3}{|c|}{0.002} & \multicolumn{2}{|c|}{0.182} \\
\hline & \multirow{2}{*}{$\mathrm{KTC}-3$} & Variables & KTC -3.1 & KTC -3.2 & & KTC -3.3 & \multicolumn{2}{|c|}{ KTC -3.4} & \multicolumn{2}{|c|}{ KTC -3.5} & KTC -3.6 & KTC -3.7 \\
\hline & & p. value & 0.035 & 0.086 & & 0.016 & \multicolumn{2}{|c|}{0.128} & \multicolumn{2}{|c|}{0.97} & 0.330 & 0.300 \\
\hline & \multirow{2}{*}{ KTC -4} & Variables & \multicolumn{2}{|c|}{ KTC -4.1} & \multicolumn{2}{|c|}{ KTC -4.2} & \multicolumn{2}{|c|}{ KTC -4.3} & \multicolumn{3}{|c|}{ KTC -4.4} & KTC -4.5 \\
\hline & & p. value & 0.641 & \multicolumn{3}{|c|}{0.080} & & & & 0.5 & & 0.010 \\
\hline & & Variables & & KTC & & & & & & & -5.2 & \\
\hline & 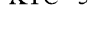 & p. value & & 0. & & & & & & & 640 & \\
\hline & & Variables & KTC -6.1 & KTC . & & KT & & & 6.4 & & -6.5 & KTC -6.6 \\
\hline & (2) - & p. value & 0.910 & 0.02 & & 0.8 & & & & & 421 & 0.029 \\
\hline & & Variables & & -7.1 & & & & & & & KTC & 7.3 \\
\hline & Alc-t & p. value & & 69 & & & & & & & 0.0 & \\
\hline & & & & p. v & & ificant at & & & & & & \\
\hline
\end{tabular}

Mehran University Research Journal of Engineering \& Technology, Volume 37, No. 2, April, 2018 [p-ISSN: 0254-7821, e-ISSN: 2413-7219] 
The results discussed above have been further analyzed making cross tabulation of those KTCs showing significant difference in terms of utilization in the results of chi-square test. According to results shown in Fig. 2, $\mathrm{KT}$ to end users through publication played significant role in terms of utilization of research capital for development. As same as discussed above, knowledge transferred by other channels also makes impact on research utilization such as organizing academic activities with industrial interest shown in Fig. 3, informal contacts of university staff with industry people shown in Fig. 4.

Results presented in Figs. 5-6 also shows impact on research utilization making transfer of knowledge in terms of personal contacts and professional contracts of academicians with industrial staff. Impact of other channels of KT for research utilization have also been identified by making cooperation with other research institutes as shown in Fig. 7, cooperation with consultancy organizations shown in Fig. 8 and sharing of lab facilities as shown in Fig. 9 also enhances the utilization of knowledge capital for development.

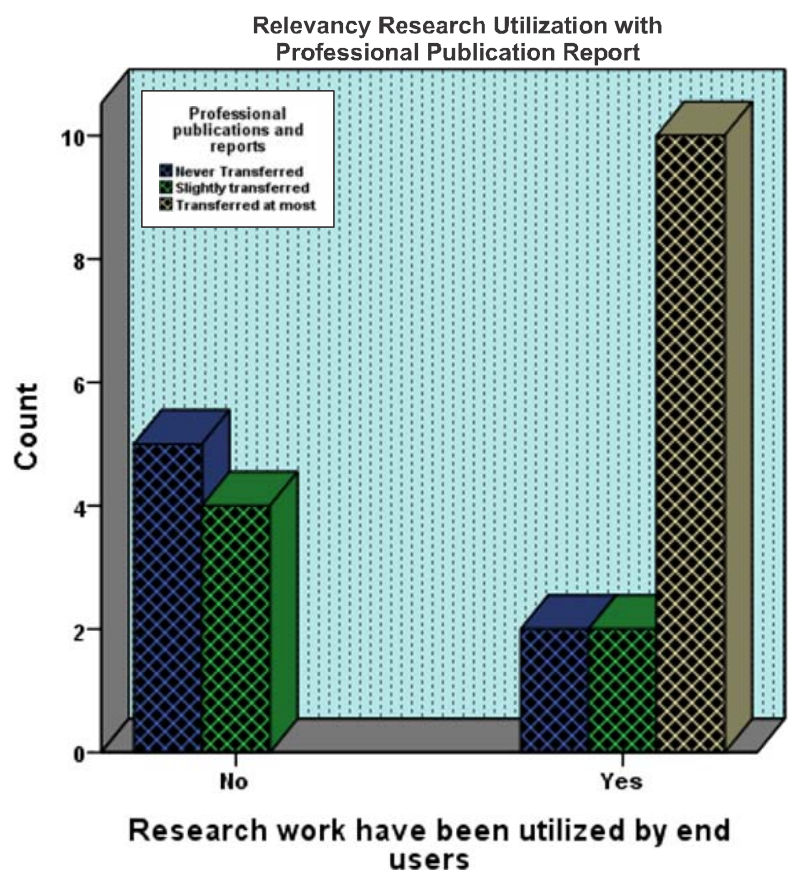

FIG. 2. ROLE OF PROFESSIONAL PUBLICATIONS TOWARDS UTILIZATION OF KNOWLEDGE CAPITAL

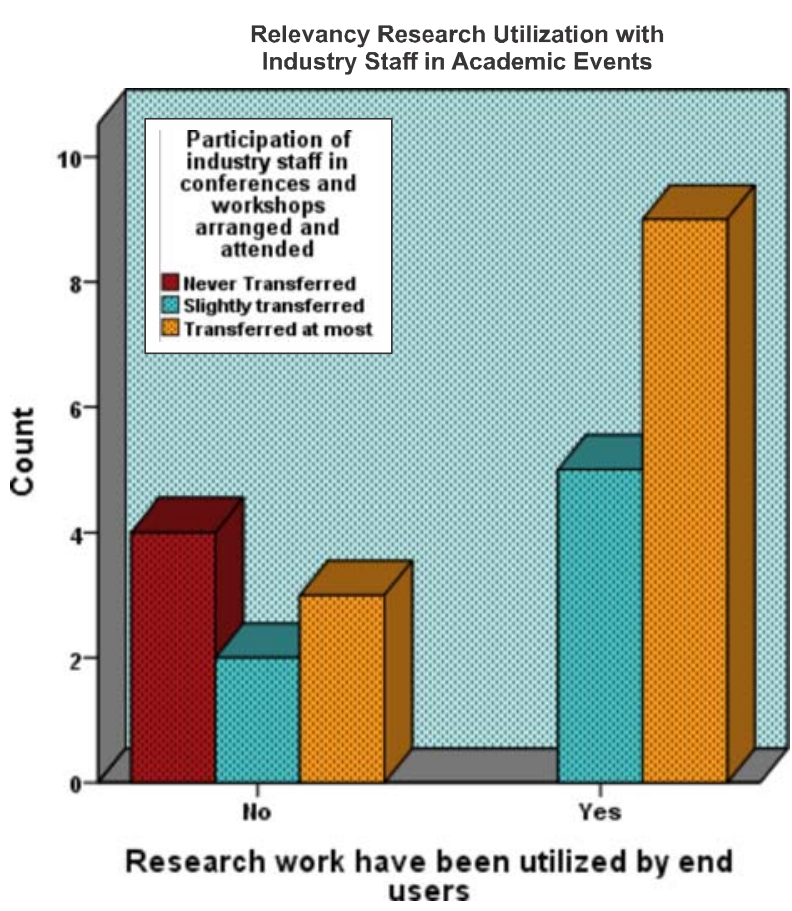

FIG. 3. ROLE OF PARTICIPATION OF INDUSTRY STAFF IN ACADEMIC ACTIVITIES TOWARDS UTILIZATION OF KNOWLEDGE CAPITAL

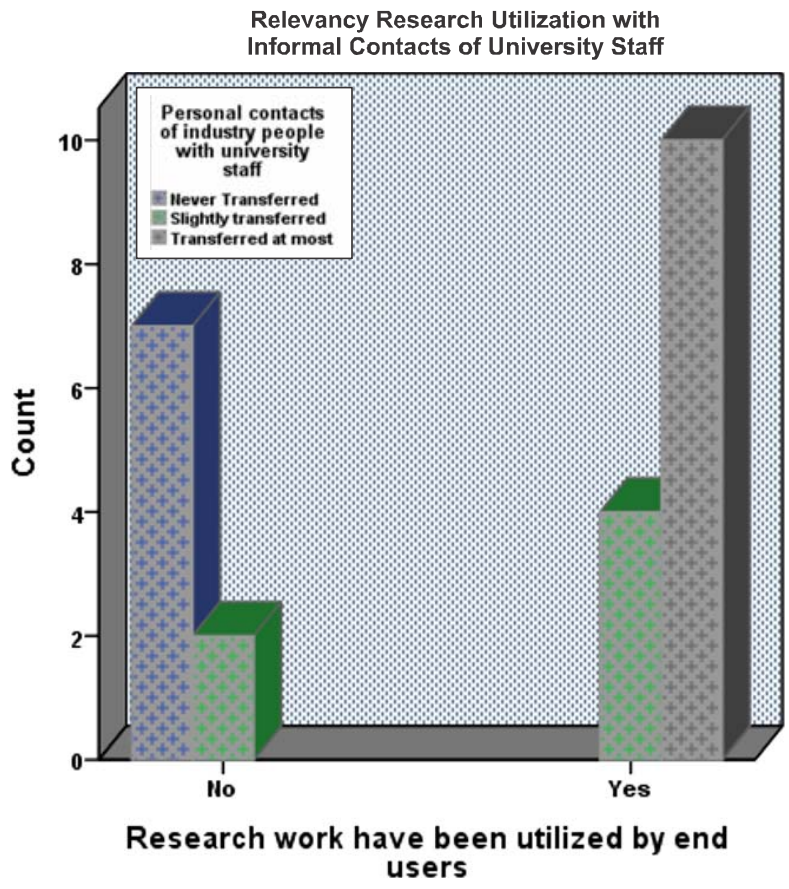

FIG. 4. ROLE OF PERSONAL CONTACTS OF ACADEMICS WITH INDUSTRY PEOPLE TOWARDS UTILIZATION OF KNOWLEDGE CAPITAL 


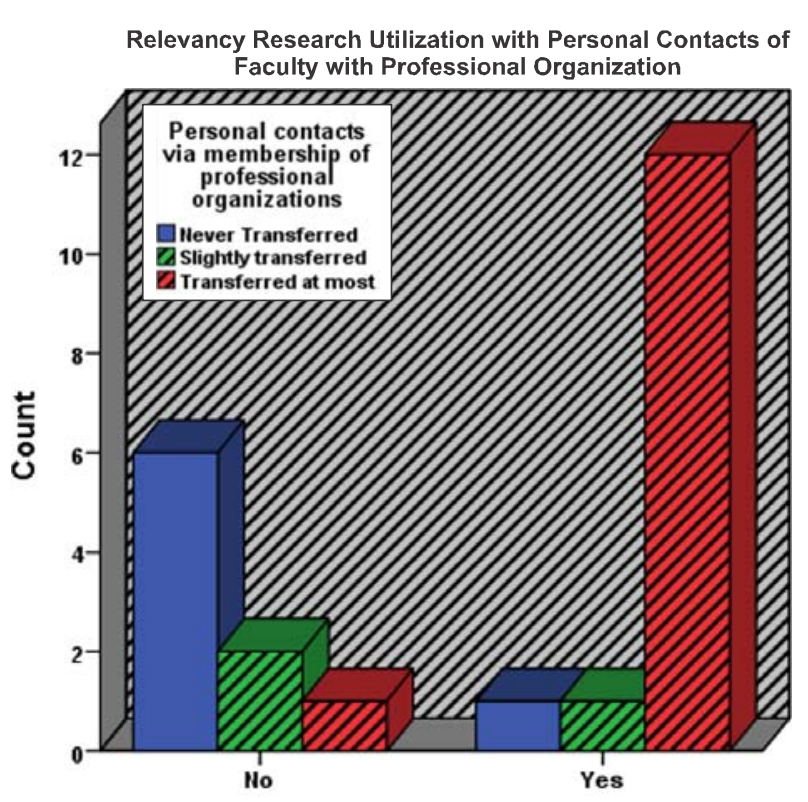

Research work have been utilized by end users

FIG. 5. ROLE OF CONTACTS VIA ALUMNI ORGANIZATIONS TOWARDS UTILIZATION OF KNOWLEDGE CAPITAL

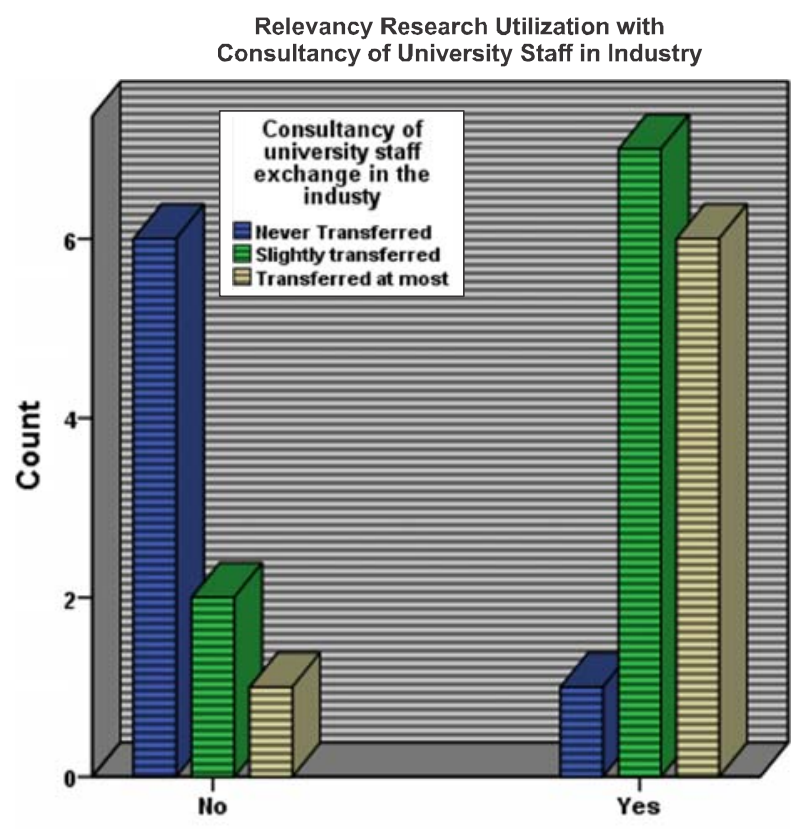

Research work have been utilized by end users

FIG. 6. ROLE OF CONSULTANCY OF ACADEMIC STAFF IN THE INDUSTRY TOWARDS UTILIZATION OF KNOWLEDGE CAPITAL

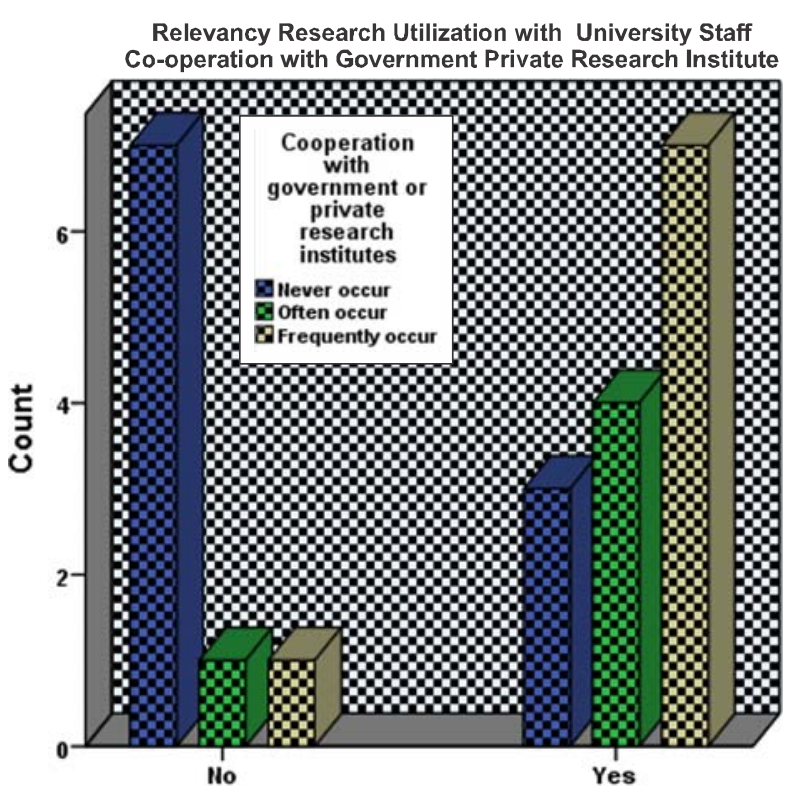

Research work have been utilized by end users

FIG. 7. ROLE OF COOPERATION WITH OTHER RESEARCH INSTITUTES TOWARDS UTILIZATION OF KNOWLEDGE CAPITAL

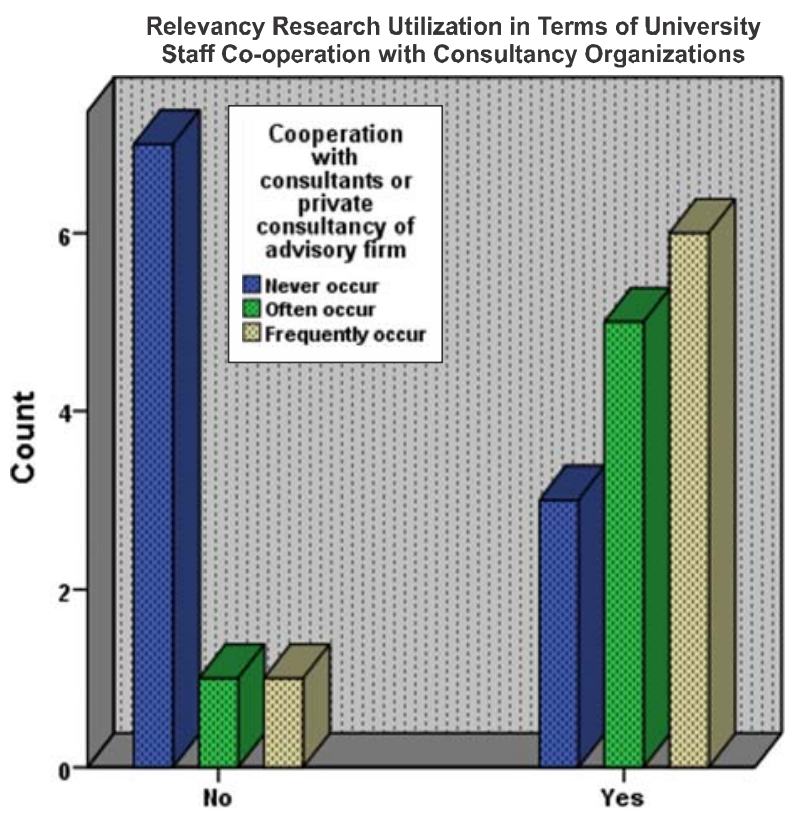

Research work have been utilized by end users

FIG. 8. ROLE OF COOPERATION WITH CONSULTANTS TOWARDS UTILIZATION OF KNOWLEDGE CAPITAL

Mehran University Research Journal of Engineering \& Technology, Volume 37, No. 2, April, 2018 [p-ISSN: 0254-7821, e-ISSN: 2413-7219] 


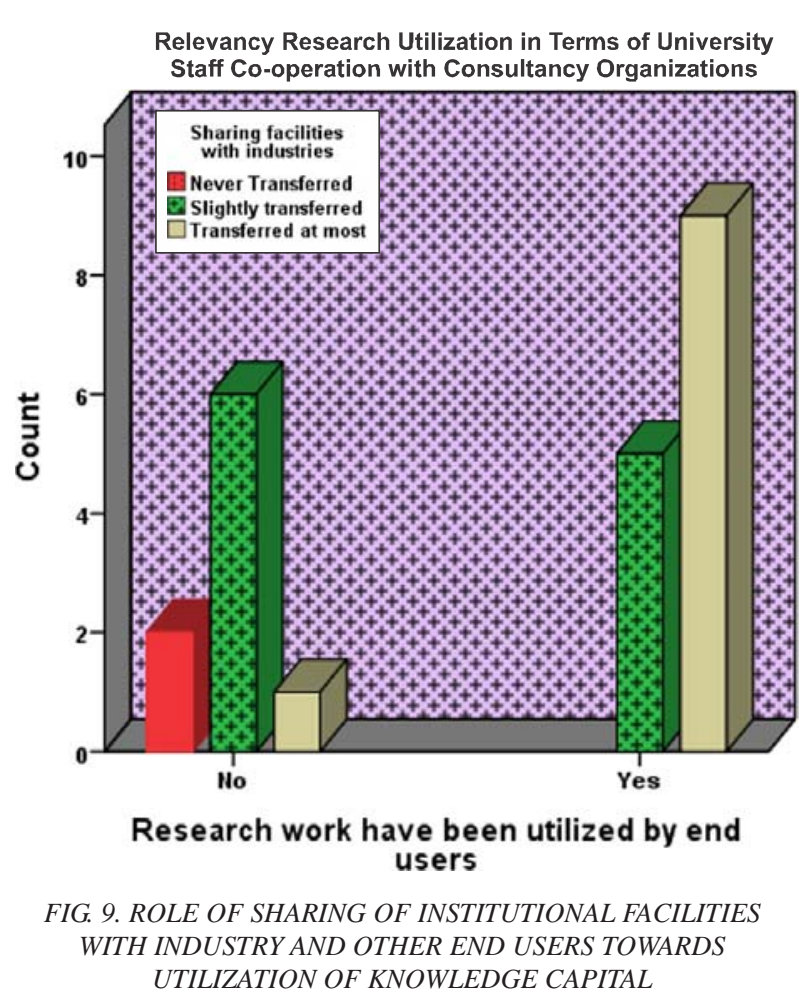

\section{CONCLUSIONS}

The assessment of KT has been observed as less focused in the literature related to developing counties. This research examined the existing level of KTCs from the universities and their role towards the development. The research findings presented valuable knowledge which explores the impact of existing policies and for development of future plane to make more effective role of universities in the knowledge creation and its transfer for development of environment sector. The KTCshave been arranged in seven groups including publications, networking, joint research work, and mobility of researchers, collaborations, intellectual property and sharing of infrastructure and so on to observe level of knowledge transfer by focusing on the environment sector. This research offers one of the exploratory studies to systematically consider on assessment of KTC from universities and their role towards development of environment sector.
It can be concluded from the KTC-1, scientific publication is seen as the most common practice of KT, and it shows that university policies are going in right way to produce the publications but along with less impact have been identified in terms of scientific publications on the utilization of knowledge capital for development of environment sector. From the KTC-2 related to networking; research presented networking of faculty with people of industry and related organization through their engagement in the conferences, workshops and trainings organized by the universities. Networking through alumni organizations are seen as less effective mode of networking.

The KTC-3 is comprised of KTCs related to the mobility of researchers. It is also an important KTC in which knowledge flows in terms of human capital, research concludes it as less effective in the existing environment. To improve the mobility of researchers at level of high qualification new policies and programs should be developed. The KTC-4 which is comprised group of KTCs related to joint work of academicians with industry people. Work in collaboration is also considered as most important practices of $\mathrm{KT}$ in which both academicians and industrialist and other related bodies transfer their expertise with each other. KTC related to IPR (Intellectual Property Rights) are focused towards assessment of KT by means of licensing and patents granted to universities. Research concludes existing academic environment is less facilitating transfer of knowledge capital by means of IPR towards the development of environment sectors.

The works done with the cooperation of personnel's of same organization and also with the other organization enhance the quality of work by increasing its utility. Finding related to transfer channel related to cooperation of faculty within the same organization and also with the other organizations, as findings concludes weak cooperation of faculty members with the outside organizations. 
At the end, channel of KT related to sharing of equipment and other infrastructure by academicians and their end users, role of TTOs (Technology Transfer Offices) in KT and assessment related to university spin-offs have been done. Research concludes sharing of facilities as effective KTC while universities and their policy making organizations have to work for development of mechanisms and infrastructure for development of university spin-offs and development of efficient TTOs.

The scope of this researchis limited on the environment sector and universities by means of knowledge producers. Future research can be done making empirical assessment in the other sectors and research organizations, contributing knowledge towards development.

\section{RECCOMMENDATIONS}

Recommendations arrived from the findings of results are presented below:

(i) Publications in terms of professional reports seems more effective for utilization of research capacities related to development goals, policy making organizations develop policies to enhance the production of professional publications.

(ii) To develop networking of faculty; universities and other policy making organizations have to focus on the improvement of alumni organizations to make it efficient and also work for the enhancement of industry people engagement in the academic events and environment related to engagement of academicians in the industry event.

(iii) Enhancement of mobility of researcher needs absorptive capacity of highly qualified graduates in the industries and other field relevant organizations. (iv) Projects on the joint research programs initiated by HEC is showing high frequency while others are seen at very less level of existence and needs to be improved by working on the industrial needs and development of universities' capabilities.

(v) The KT in terms of licensing and patents can be developed structuring policies and infrastructure to support the commercialization of academic knowledge.

(vi) Policies should be developed in favor of research work in cooperation to increase the level of work in co-operation in the universities with academic and industrial partners.

\section{ACKNOWLEDGEMENT}

This research is part of $\mathrm{PhD}$ research Funded by Higher Education Commission of Pakistan. Authors are thankful for cooperation of PhD faculty members of HEIs in Sindh offering degrees in field of environment for sharing their valuable time for interviews.

\section{REFERENCES}

[1] Lashari, J.H., Bhutto, A., and Rashdi, R.S., "Five Stage Model for Assessment of Research Utilization”, International Journal of Scientific \& Engineering Research, Volume 7, No. 1, pp. 12-20, 2016. Agrawal,A.K., “University to Industry Knowledge Transfer: Literature Review and Unanswered Questions”, International Journal of Management Reviews, Volume 3, No. 4, pp. 285-302, 2001.

[3] Katunga, M.M.D., and Muhigwa, J.B., "Scientific Research Publishing”, Sage Publications, pp. 2-12, 2012. 
[4] Ardakani, F.B., Yarmohammadian, M.H., Abari, A.A.F., and Fath, K., "Internationalization of Higher Education Systems”, Procedia Social and Behavioral Sciences, Volume 15, No. 3. pp. 165-169, 2011.

Lashari, J.H., Bhutto, A., and Qazi, M.M., “Timely PostGraduate Degree Completion: A Case Study ofJamshoro Education City”, Mehran University Research Journal of Engineering \& Technology, Volume 32, No. 1, January, 2013.

[6]

Chagnon, F., Pouliot, L., Malo, C., Gervais, M.J., and Pigeon, M.È., “Comparison of Determinants of Research Knowledge Utilization by Practitioners and Administrators in the Field of Child and Family Social Services”, Implementation Science, Volume 5, No. 1, pp. 32-41, 2010.
[13] Gübeli, M.H., and Doloreux, D., “An Empirical Study of University Spin-Off Development”, European Journal of Innovation Management, Volume 8, No. 3, pp. 269-282, 2005.

[14] Senker, J., Faulkner, W., and Velho, L., "Science and Technology Knowledge Flows between Industrial and Academic Research: AComparative Study”, Capitalizing Knowledge, pp. 111-132, 1998.

Monjon, S., and Waelbroeck, P., "Assessing Spillovers from Universities to Firms: Evidence from French FirmLevel Data”, International Journal of Industrial Organization, Volume 21, No. 9, pp. 1255-1270, 2003.

Cohen, W.M., Nelson, R.R., and Walsh, J.P., "Links and Impacts: The Influence of Public Research on Industrial R\&D”, Management Science, Volume 48, No. 1, pp. 1-23, 2002.

Polt, W., Rammer, C., Schartinger, D., Gassler, H., and Schibany, A., "Benchmarking Industry-Science Relations in Europe-The Role of Framework Conditions”, Science and Public Policy, Volume 28, No. 4, pp. 247-258, 2001.

Calvert, J., and Patel, P., ”University-Industry Research Collaborations in the UK”, University of Sussex, 2002.

[19] Landry, R., Lamari, M., and Amara, N., "The Extent and Determinants of the Utilization of University Research in Government Agencies”, Public Administration Review, Volume 63, No. 2, pp. 192-205, 2003.

[20] Butcher, J. and Jeffrey, P., "The Use of Bibliometric Indicators to Explore Industry-Academia Collaboration Trends Over Time in the Field of Membrane Use for Water Treatment”, Technovation, Volume 25, pp. 1273-1280, 2005.

[21] Rappert, B., Webster, A., and Charles, D., "Making Sense of Diversity and Reluctance: Academic-Industrial Relations and Intellectual Property”, Research Policy, Volume 28, No. 9, pp. 873-890, 1999. 
[22] Mills, A.J., Durepos, G., and Wiebe, E. (Editors), "Encyclopedia of Case Study Research", Sage Publications, 2009.

[23] Cohen, D., and Crabtree, B., "Qualitative Research Guidelines Project”, Routledge, 2006.

[24] Neuman, A., Shahor, N., Shina, I., Sarid, A., and Saar, Z., "Evaluation Utilization Research-Developing a Theory and Putting it to Use”, Evaluation and Program Planning, Volume 36, No. 1, pp. 64-70 2013.
[25] Hinton, P.R., ”Statistics Explained”, Routledge, 2014.

[26] Jothikumar, N., Lowther, J.A., Henshilwood, K., Lees, D.N., Hill, V.R., and Vinjé, J., "Rapid and Sensitive Detection of Noroviruses by Using TaqMan-Based OneStep Reverse Transcription-PCR Assays and Application to Naturally Contaminated Shellfish Samples”, Applied and Environmental Microbiology, Volume 71, No. 4, pp. 1870-1875, 2005. 